\title{
Research on Strategic Control of Green Cost Based on Ecological
}

\section{Economy}

\author{
Fengzhou Wang ${ }^{1, a}$, Meifang Zha ${ }^{1, b}$ \\ ${ }^{1}$ School of Business Administration, Jimei University, Yinjiang Rd. 183, Xiamen, China \\ a email: fzhwang@jmu.edu.cn, ${ }^{b}$ email: mfazha@163.com
}

\begin{abstract}
Key words: eco-economic; green cost; Strategic control framework; Environmental Analysis; Value chain analysis; Cost Driver Analysis

Abstract: Under the background of eco-economic development, enterprises are under the pressure of sustainable development exerted by multiple stakeholders and it is imperative to establish a model of eco-economic development of enterprises. It is essential for enterprises to build a eco-economic development model in order to achieve a win-win economic and environmental benefits. This paper discusses the existing problems of green cost management firstly, and puts forward the strategic control framework of green cost.
\end{abstract}

\section{Introduction}

According to the basic view of property rights theory, the root cause of environmental problems is the public nature and scarcity of environmental resources themselves. Because of the vague nature of the property rights of environmental resources, people do not need to pay corresponding costs when using and infringing the assets. Therefore, through the policy of legislation to promote the internalization of external costs. In recent years, the government has introducing relevant policies unceasingly, combining the administrative measures and economic measures to strengthen the intensity and efficiency of environmental protection, and increasing administrative fees or fines for heavily polluting enterprises through administrative legislation, in addition, increasing investment in R\&D fund for green technologies and giving administrative awards to enterprises that have made outstanding contributions to environmental protection. Economic instruments are more efficient, for example, those enterprises which adopt the green business model could enjoy lower-cost financial services resources, the government project are focused on those enterprises adopting a green management model, etc., they guide their enterprises to abandon or re-integrate the traditional industries with serious sewage discharge and transform themselves into a green management mode by introducing resources into the green industry and eventually realizing the eco-economic development mode.

The development of eco-economy relies mainly on the role of enterprises play, the economic activities of enterprises mainly include the production and operation activities, where there is the active track of enterprises, there is the existence of costs. Therefore, there is a close relationship between the establishment of eco-economic development model and green cost control, which will contribute to the establishment and development of the present and future eco-economic model through the control of green costs. This article presents the strategic framework of green cost control of enterprises trying to establish eco-economic development mode, which includes environmental analysis strategy, value chain analysis strategy and cost driver analysis strategy. 


\section{Green Cost Overview}

The basic concept of green cost. Green cost management is a new sustainable cost management mode derived from the development of ecological economy. The Green Accounting Theory came into being in the late 1980s, and it has been specifically described that we should study the combination of ecological environment with product measurement and management of resource consumption. Cost is one of the important factor in accounting elements, "green cost" research will also enter the people's horizons. Guo Daoyang (1997) ${ }^{[1]}$ first mentioned the concept of "green cost" in his "Preliminary Study of Green Cost Control". Wang Jianming et al. (2003) ${ }^{[2]}$ also defined the concept of green cost as " Green costs which is based on the principle of responsible for the environment, are the costs of measures taken or required to manage the impact of business activities on the environment and other costs that are incurred as a result of the enterprise's implementation of environmental objectives and requirements ". Li Ming (2015) ${ }^{[3]}$ mentioned two perspectives on green costs, namely the concept of total cost and cost elements. I agree with the former, that is, green costs should be the sum of product manufacturing costs and environmental resources consumption, because the green cost is a cost assembly, continuous reduction of the green cost is the goal of green cost control activities which achieve by fully grasp the green Cost drivers, and targeted control. The basic cost of green costs include: environmental prevention fees, environmental management fees, environmental protection technology research fees, environmental assessment fees, environmental fines, environmental sewage charges and so on.

In that context, the mode of production in our country is extensive production, in addition, the awareness of environmental protection was poor, which lead to the opposite relationship between economic benefits and environmental benefits. "green cost" is just a simple conceptual situation. In the 21st century, it is the social responsibilities that enterprises should implement green production, provide green services and create a green environment ${ }^{[4]}$ With the gradual awakening of environmental awareness and the intensification of environmental protection policies, in order to meet the policy standards, enterprises will have to pay for maintenance and prevention costs, pay for loss compensation and damage management fees, pay for costs caused by man-made damage to the environment, and pay the ecological environment of the paid use fee ${ }^{[5]}$.However, it will bring positive results to environmental protection and enterprise economic benefits at the same time through sound planning and scientific management, green production not only has long-term indirect benefits, but may even bring short-term direct benefits ${ }^{[6]}$. Therefore, this paper puts forward the framework of strategic control of green costs, providing theoretical guidance for the practice of green cost control.

The current green cost control problems. At present, although many enterprises in our country are beginning to pay more and more attention to green cost management, the research and application of green cost management are still in their infancy, so there are still some problems in the application of green cost management.

The concept of strategic management is narrow. In many enterprises, managers with strategic management concepts are concentrated in the top team of leaders. Each departmental leader does not have the strategic vision and believes that the senior leaders should formulate strategy and assign specific tasks, and regards themselves as implementer of the strategic plan, dose not participate in the strategic formulation initiative. The concept of strategic management is relatively narrow, and many strategists focus only on capital, technology, products and customer needs, ignoring other aspects of the company's internal and external impact on strategic effectiveness.

There is a lack of awareness of green costs. Green cost awareness is the forerunner of cost strategy control. Lack of green cost awareness will directly lead to the collapse of green cost 
strategic control system. Based on the current cost accounting system, the scope of cost confirmation measurement is limited to raw material costs, labor costs, machine costs, Expenditures and environmental performance can not be independently represented, but rather dispersed or hidden in other projects ${ }^{[7]}$, strategic managers often make management decisions based on the information provided in cost reports, and on the basis of which management members' thinking basically based on the traditional areas of economic costs, their awareness of green costs is weak. Business leader need to stand on the strategic level, leading the entire business development direction. For enterprises, it is necessary to cultivate the full awareness of green costs and advocate the concept of sustainable development within the enterprise, so as to infiltrate the awareness of green costs into the whole process of daily business activities and raise the awareness of green costs.

The green cost system is underdeveloped. The role of the green cost system is to regulate the procedures for the confirmation, measurement and recording of green costs and is the institutional basis for green cost management. First of all, there is no clear system standard about how to deal with the green cost in our country. The backwardness of the system construction is not only because of the lack of practice but also the lack of theoretical research. In practice, compared with the capital, technology and products, the environmental elements are not the emphasis of managers, as the result, green cost management is submerged in other management activities. Although there are a lot of theoretical studies on green cost and green accounting in theory research, there is no unified and complete theoretical system, which restricts the construction of a unified national-level cost system. Secondly, due to the lack of a unified national green cost system, there is no uniform guideline for enterprises in the confirmation and measurement of green costs, therefore, there is no direction for the construction of a green cost management system within the enterprise which restricts the control of green costs.

There is not enough talent pool. Green cost management personnel are the organizers, planners and supporters of the strategic environmental management activities, are the guarantee and driving force of the application of strategic environmental cost management, at present, due to lack of qualified personnel, there is no motivation for the application of green cost strategic control. The reasons for the shortage of talents mainly include: a) The lack of theoretical education. Currently, there is no comprehensive teaching of green cost management in the domestic higher education system, which directly leads to the shortage of students' knowledge of green cost. Due to the lack of conceptual understanding of strategic environmental cost management and in-depth exploration of the basic content system and application methodologies, it is difficult to have a strategic vision in practice and this restricts the practical application of environmental cost management. b) Lack of vocational training. Many enterprises do not carry out vocational training on green cost management, because some enterprises lack awareness of environmental costs and do not need to implement green cost strategic control activities. Some enterprises unconsciously carry out environmental costs management which only be regarded as an adjunct to other activities, is not listed separately as an element of strategic management, therefore, the application of strategic control of green costs is limited. 


\section{Green Cost Strategic Control Framework Based on Eco-Economy}

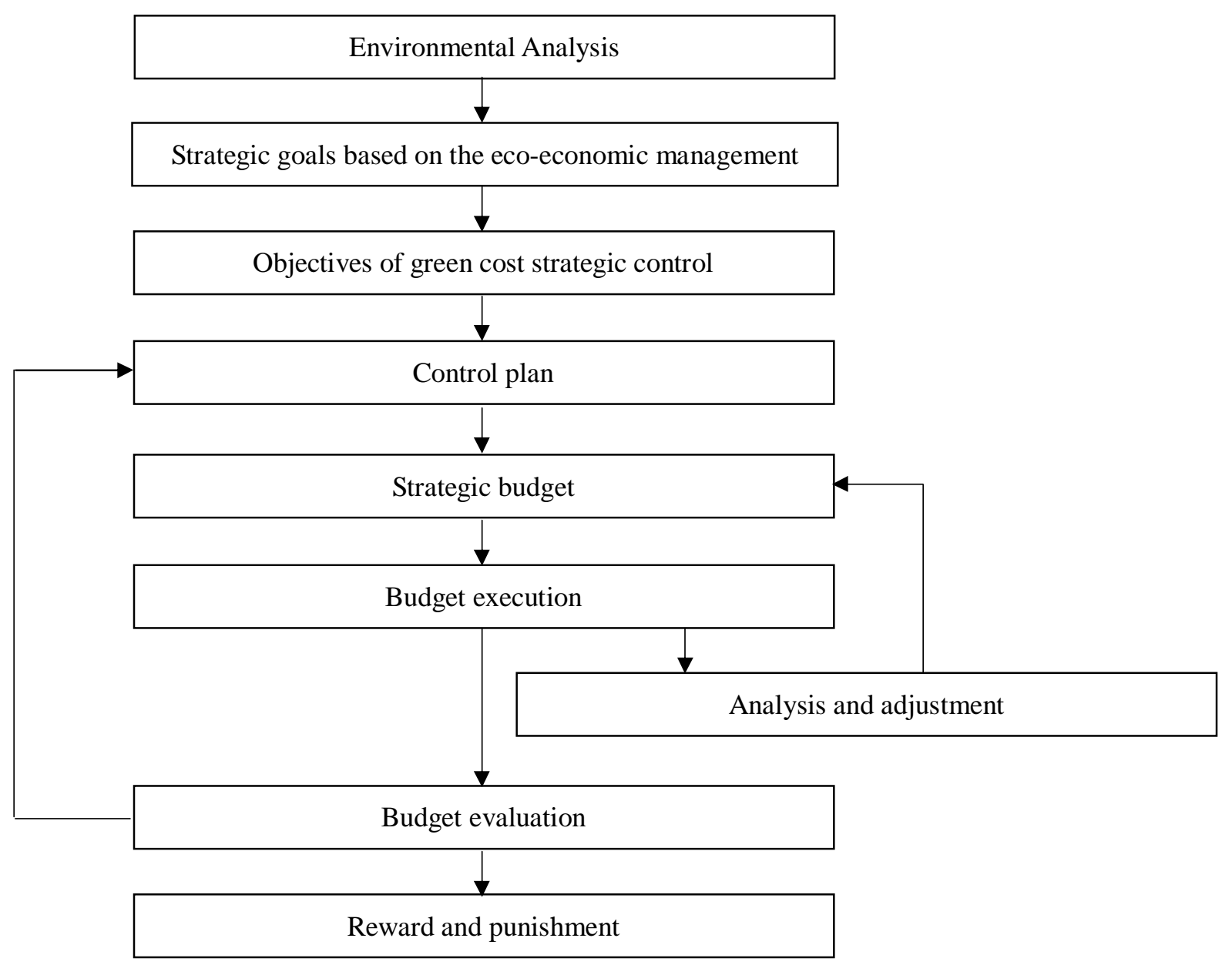

Fig 3.1 Green Cost Strategic Control Framework Based on Eco-economy

As shown in Figure 3.1, the cost strategy control framework diagram is consist of environmental analysis, organizational management and operation of the ecological strategy goals, green cost strategy control objectives, control programs, strategic budget, budget implementation, implementation analysis and adjustment, the budget assessment evaluation, And encouragement and reward. Environmental analysis is the starting point and the basis for the strategic control of green costs, including macro environment analysis, industrial environment analysis and competitive environment analysis. Through environmental analysis, the strategic decision makers could accurately grasp the current situation and characteristics of ecological and economic development, combined with the advantages and disadvantages of enterprises, establish the ecological strategic objectives of the organization and management which formulate a green cost strategy control objectives based on. After the establishment of the strategic goal, the next one is the determination of cost control programs, first of all, it is need to determine the relevant responsibility department, the responsibility department could submit a cost control program which will be audited by the higher authorities, through two-way communication to determine better cost control program. The strategic budget is the basis for cost control and also the basis for performance appraisal of the budget execution. According to the detailed rules of the cost control plan, managers determine the strategic budget and quantify the various control indexes so that each responsible department can have a clear cost control during the budget execution. Through real-time monitoring and analysis of 
the implementation of the budget, if the implementation of the budget deviates from the actual situation, managers should timely analyze the causes of the deviations, and if it is a deviation caused by the implementation of the procedures, they should improve the implementation procedures in a timely manner, if the deviation is caused by the unreasonable budget setting, they should adjust the strategic budget in time. Finally, managers need to assess the results of the budget implementation, evaluate the completion of the strategic budget, and reward or penalize the relevant responsible parties based on the results of the assessment. In short, the framework of green cost strategy control contains many elements. This article is limited in space and will only analyze the starting point of green cost strategy control, including environmental analysis, value chain analysis and cost drivers analysis.

Environmental Analysis Strategy of Green Cost Strategic Control Environmental analysis is the starting point for a strategic control of green costs. The purpose of the analysis of the external environment is that grasping the status quo and the changing trend of the environment, so managers can take advantage of opportunities and avoid the possible threats to the environment. Environmental analysis is the primary analysis of the survival and development of enterprises, including the macro environment, industrial environment and competitive environment.

Macro-environment analysis. Macroeconomic analysis includes political and legal factors, economic factors, social and cultural factors as well as technical factors: a) Political and legal factors. The environmental policies promulgated by the government indicate that the economic model will shift towards the eco-economic model, managers should pay attention to administrative fees and penalties for environmental pollution control system, which is closely related to the cost of environmental losses in the latter part of the enterprise; b) Economic factors, including the analysis of the current industrial structure, the analysis of government subsidies, the national wage level; c) Social and cultural factors, including consumer psychology, lifestyle and values; d) Technical factors, including the national science and technology system, science and technology policy, science and technology development trend. It is very important that analyzing the national science and technology system and policies to enterprises to update or introduce advanced technologies.

The industrial environment analysis. The analysis of industrial environment is an analysis of the environment in which one or more industries are competing. The main points are as follows :a) In the life cycle stage, according to Porter's competition theory, the industry goes through four stages, the period of introduction and the period of growth, maturity and recession, the business risks and management strategies adopted in each stage will be different, based on this, the limited resources of enterprises will be optimally allocated. b) Analysis of industrial competitiveness, including potential entrants threats, threat of alternatives, supplier, buyer bargaining power, competition among existing enterprises and key success factors, after which managers can determine what kind of strategic response an enterprise should adopt.

Competitive environment analysis. Analyzing the competitive environment can be carried out in two aspects: a) Analyzing the competitors 'future goals, assumptions, current strategies and capabilities from the perspective of a single enterprise, obtaining competitors' current market position, financial capability and identifying competitors' misunderstandings and blind spots, finding the strengths and weaknesses of competitors; b) From the perspective of strategic group analysis, a strategic group refers to a group of companies that adopt the same or similar strategy in one strategy or have the same strategic characteristics ${ }^{[8]}$, and through strategic group analysis, it is helpful to companies to judge the current competitive position, positioning and profitability of enterprises in the industry, take the initiative to find distant and near competitors, understand the mobility barrier between strategic groups. 
Strategy of Value Chain Analysis of Green Cost Strategy Control. The scope of strategic control of green costs is comprehensive and extensible, mainly including external value chain analysis and internal value chain.

The external value chain. External value chain refers to the entire process an industry from the purchase of raw materials to the final consumption of creating value of the collection. First of all, enterprises should establish strategic cooperation with the upstream value chain. According to Porter's value chain theory, enterprises connect with the upstream value chain through procurement, suppliers not only have a serious impact on the green costs of enterprises, but also provide enterprises with potential opportunities to control environmental costs and improve environmental performance. Therefore, enterprises should establish strategic cooperation with upstream suppliers and select suppliers through the establishment of green procurement performance evaluation standards in order to share the cost of environmental control and environmental risks together. Second, enterprises should establish strategic cooperation with downstream value chains. Enterprises need to establish a green distribution system to minimize the length of distribution channels, make full use of e-commerce features fast, cheap and efficient network sales. Establish a strategic partnership with consumers, enterprises link with the downstream value chain to achieve convergence through the marketing, based on the "producer responsibility extension" of the legal system, enterprises have to bear part of the waste generated by the downstream value chain processing costs, therefore, they must keep abreast of the needs of consumers and market trends of products, adjust their own production processes, establish product recycling and consumption of waste resources in the recovery process with consumers together.

The internal value chain. Eco-economic model is different from traditional economic development model, it is a closed-loop system. Product life cycle is divided into product design, procurement, production, sales and waste disposal, through the establishment of overall thinking, enterprises have to determine the green cost control strategy of the various stages in order to achieve the green cost optimization of the full life cycle, and finally achieve economic benefits and win-win environmental benefits. a) Product design stage. The green cost control in the product design stage belongs to ex ante control, which is the most effective phase control in the whole control activity, which determines the efficiency and effect of control and ex post control. Product design determines green cost from the consumption of raw materials, manufacturing processes, use and service quality, recycling and waste. Therefore, the R \& D personnel should regard the green philosophy as a guide, give full consideration to the compatibility, easy degradation, renewable and recycling of the raw materials used in the production of the product, to ensure that raw materials are environmentally friendly, non-toxic, non-radioactive. b) Product procurement phase. Products in the design is completed, it is necessary to purchase raw materials needed for production in accordance with predetermined standards. Enterprises should fully analyze and assess the supplier's environmental information, and optimize the procurement of raw materials channels. In addition, enterprises should set a reasonable batch of orders, strive to achieve zero inventory under the premise of reducing inventory, in particular, to reduce volatile and easy to leak the material inventory is not conducive to environmental protection, as far as possible to reduce the environmental damage in the procurement link. c) Product production stage. Cleaner production is a very effective way for enterprises to control the green cost in the production stage. Enterprises should continuously apply the comprehensive preventive environmental strategy in the production and services process, improve the production technology and supporting environmental protection equipment, and try to use renewable, alternative energy materials, reduce the consumption of 
non-renewable energy, reduce their quantity and toxicity as much as possible before the waste is discharged. d) Product sales stage. In the product sales stage, companies need to focus on two processes, one is that product left the production process to reach buyers. First of all, packaging, businesses should try to reduce the production of packaging waste, improve reuse and recycling rate, try to use reusable, easily degradable, non-toxic packaging materials, choose to use the package with less resource and energy consumption, renewable and less impact on the environment. Second, transport vehicles, enterprises should scientifically select transportation means and transport routes and adopt clean fuels whenever possible so as to avoid the harm to the environment caused by the leakage of materials in transit. Another one is the process of product use. Enterprises should give full play to the guidance of consumers, and gradually enhance consumer awareness of green consumption. e) Product obsolescence stage. In the final stage of discarding products, enterprises should give full consideration to how to recycle and properly dispose of discarded products, implement recycling strategies for discarded products, and establish a recycling system for discarded products. By reusing recycled products, enterprises could obtain high economic value with lower recovery costs, so that resources can be returned to the resource chain.

Cost Driver Analysis of Green Cost Strategic Control. The choice of cost drivers is the key. By analyzing the drivers of green cost in the enterprise and controlling the main value drivers in the value chain, enterprises can obtain the "green comparative advantage." Based on the classification of green cost drivers by Liming (2015), this paper re-sorts the classification of green cost drivers. The green cost drivers can be divided into necessary cost drivers and over-consumption cost drivers, for the two types of cost drivers, the control strategy should be different. Necessity Environmental cost drivers include necessary human resources, material resources, natural resources and necessary expenditures on environment maintenance, over-consumption cost drivers include excessive consumption of human resources, excessive consumption of material resources, excessive consumption of natural resources, environmental protection, failure of expenditure. Among them, the former is the foundation, which determines the quantity and structure of the green cost, the letter is the cost incurred during and after the execution of the plan. The key is to divide the scope of each type of cost drivers and allocate them to operations reasonably so as to improve the controllability of green costs.

The cost drivers of necessity. In terms of necessity, it refers to the resource consumption that is necessary in normal production. Before production, based on the analysis of the entire environment, enterprises should clearly define their position in the industry and rank the top enterprises in the industry as the benchmark. If they combine the actual production and operation scale and business volume of the enterprises, establish the benchmark for each cost factor one by one and calculate the target control value for each cost item. When calculating the target control value, it is necessary to have the characteristics of difficulty and feasibility, that is, the control target that can not be easily achieved through the excellent cost control work can be achieved. Finally, they can determine the best quantity and structure of traditional resources and environmental resources. In addition, the selected relevant departments should be targeted to control the cost. On the one hand, leaders have to assign the task of cost control objectives to the relevant departments or personnel, and they formulate feasible plans of action to accomplish the goal and task, which is approved and executed on the basis of the examination and approval of the superior competent department. On the other hand, the competent departments at higher levels shall conduct dynamic monitoring on the implementation of the program of action.

Over-consumption cost drivers. Based on the control of the necessary cost drivers, the enterprises also need to focus on controlling the cost drivers of excess costs. The control of the 
excessive cost is concentrated on the implementation of the strategic plan, the key lies in implementing the quantitative targets for various types of resource consumption that have been identified in the strategic plan. If the control plan is not implemented in accordance with the established steps, there will be excessive costs, including excessive human resources, material resources, natural resources and legal costs related to environmental damage, fines, compensation and additional governance spending. In order to achieve the goal of green cost control, it is necessary to supervise and maintain the normal operation of daily production and operation of the enterprise so as to ensure the smooth progress of the cost control plan. Enterprises should pay attention to the cultivation and promotion of environmental awareness during the product life cycle and call on all employees to participate in the process of product quality management so that employees can assume the responsibility of environmental protection while taking responsibility for quality.

\section{Conclusions}

The advent of ecological society indicates that the development of human society and environmental protection are no longer the opposite aspects of contradictions. Environmental protection and sustainable development are the common choices of human society. Through the excellent management techniques, the common development of economic benefits and environmental benefits can be achieved. In this context, the study of green cost control has some theoretical and practical significance. Based on the eco-economic development model, this paper proposes a framework of green cost strategy control, including environmental analysis, value chain analysis and cost driver analysis. The follow-up study of the author hopes to further deepen and improve the green cost strategic control system through the research on the environmental performance evaluation system based on the eco-economy.

\section{Acknowledgements}

This work was financially supported by the Key Projects of the Fujian Science and Technology (2010R0076) and the Key Projects of the Fujian Science and Technology (2014R0110).

\section{References}

[1] Guo Daoyang. Green Cost Control [J]. Accounting Monthly, 1997 (05): 3-7.

[2] WANG Jian-ming, YE Qing-song, ZOU Xiao-wu. Study on Green Cost Management Based on Strategic Cost Management [J]. Science \& Technology Management, 2003 (11): 96-99.

[3] Li Jingming. Research on the Stratified Control Model of Green Cost of Enterprises - A Case Study of SM Paper [J] .Academy Monthly, 2015 (22): 11-15.

[4] Li Guihua. Green Management: Corporate Social Responsibility in the 21st Century [J]. Inner Mongolia Statistics, 2000 (05): 6-7.

[5] Hu Zhenhua, Yang Xiaoming. Internalization of Environmental Costs and International Green Trade [J] .International Trade Issues, 2001 (09): 48-54.

[6] Yan Hong, Ren Peiyu, Li Xiangdong, Ye Runqiang. Cost-effectiveness of Green Production: An SMP Case Study [J]. Economic Restructuring, 2001 (04): 89-91.

[7] Xie Delin.Enterprise green management system and environmental accounting [J] .Accounting Research, 2002, (1): 48-53,47. 
[8] LI Hai-jian, NIE Hui-hua. The Source of Enterprise Competitive Advantage and Its Strategic Choice [J]. China Industrial Economics, 2002, (9): 5-13. 